\title{
Is it safe to delay testosterone replacement therapy in pandemic times?
}

Fernando Nestor Facio Junior ${ }^{1}$ (iD) Luis Cesar Fava Spessoto ${ }^{1}$

1. Professor de Urologia, Departamento de Urologia. Faculdade de Medicina de São José do Rio Preto (FAMERP FUNFARME), São José do Rio Preto, SP, Brasil.

Unprecedented measures have been adopted by several countries to curb the spread of the virus and control the increase in the number of patients infected with COVID-19, making the population's health more vulnerable'.

Daily data show that the entire population with SARS-CoV2 is composed of $62 \%$ of men ${ }^{2}$. This had a great impact on the quality of life of men aged over 60 , as $66.2 \%$ can develop severe forms of this disease $^{3}$. Especially in this group, attention should be increased, including social isolation recommended by health authorities.

In this context, men seem to be more susceptible to infection and mortality compared to women ${ }^{4}$. Hormonal effects may have a pathophysiological role in association with SARS-CoV-2; thus, this disease could worsen hypogonadism with depletion of androgenic action, triggering a severe or even fatal course of the disease $e^{4}$. Androgen deficiency increases with age and hypogonadism can negatively affect the functions of multiple organs and quality of life, therefore, it is necessary to maintain testosterone replacement therapy ${ }^{5}$.
It is known that a low plasma testosterone concentration associated with comorbidities such as obesity, hypertension, diabetes, and respiratory diseases are all highly prevalent in patients with COVID-19. In this context, low levels of testosterone can reduce muscle activity in the respiratory system, general strength, and exercise capacity ${ }^{6}$, while normal levels of circulating testosterone show a protective effect on the respiratory system ${ }^{7}$.

Evidence indicates that testosterone, capable of modulating the expression of the angiotensin-converting enzyme 2 (ECA2), is activated and negatively regulated by the coronavirus spike protein, which allows its penetration into epithelial cells and the myocardium ${ }^{8}$.

From a psychogenic point of view, depression, irritability, and concentration difficulties are some of the side effects that low serum testosterone levels can cause $^{9}$. The deficiency of this hormone in men suggests changes in effective processing and in the regulation of emotional decision making ${ }^{10}$. In such cases, it is essential to maintain adequate patient monitoring, including an effort to avoid treatment abandonment and probable hypogonadism relapse. 
Therefore, as we face these challenges and the uncertainties regarding the time necessary for social isolation and possible delays in personal visits to clinics, we can offer online appointments to answer questions regarding the acquisition of prescriptions, doses, and maintenance of therapy. During this pandemic, low testosterone levels in men older than 60 years of age can further aggravate the health status of these patients, who require specialized care, social isolation, and emotional support.

\section{REFERENCES}

1. Zhu N, Zhang D, Wang W, Li X, Yang B, Song I, et al; China Novel Coronavirus Investigating and Research Team. A novel coronavirus from patients with pneumonia in China. N Engl | Med. 2019;382(8):727-33.

2. Zhou F, Yu T, Du R, Fan G, Liu Y, Liu Z, et al. Clinical course and risk factors for mortality of adult inpatients with COVID-19 in Wuhan, China: a retrospective cohort study. Lancet. 2020;395(10229):1054-62.

3. Guan WJ, Liang WH, Zhao Y, Liang HR, Chen ZS, Li YM, et al; China Medical Treatment Expert Group for COVID-19. Comorbidity and its impact on 1590 patients with COVID-19 in China: a nationwide analysis. Eur Respir . 2020;55(5):200547.

4. Salonia A, Corona G, Giwercman A, Maggi M, Minhas S, Nappi RE, et al. SARS-CoV-2, testosterone and frailty in males (PROTEGGIMI): a multidimensional research project. Andrology. 2020. doi: 10.1111/andr.12811.

5. Bhasin S, Brito JP, Cunningham GR, Hayes F), Hodis HN, Matsumoto AM, et al. Testosterone therapy in men with hypogonadism: an Endocrine Society Clinical practice guideline. J Clin Endocrinol Metab. 2018;103(5):1715-44.

6. Montanõ LM, Espinoza |, Flores-Soto E, Chávez |, Perusquiá M. Androgens are bronchoactive drugs that act by relaxing airway smooth muscle and preventing bronchospasm. | Endocrinol. 2014;222(1):1-13.

7. Mohan SS, Knuiman MW, Divitini ML, James AL, Musk AW, Handelsman DJ, et al. Higher serum testosterone and dihydrotestosterone, but not oestradiol, are independently associated with favourable indices of lung function in community-dwelling men. Clin Endocrinol (Oxf). 2015;83(2):268-76.

8. Pozzilli P, Lenzi A. Testosterone, a key hormone in the context of COVID-19 pandemic. Metabolism. 2020;108:154252.

9. Kumar P, Kumar N, Thakur DS, Patidar A. Male hypogonadism: symptoms and treatment. | Adv Pharm Technol Res. 2010;1(3):297-301.

10. Mueller SC, Grissom EM, Dohanich GP. Assessing gonadal hormone contributions to affective psychopathologies across humans and animal models. Psychoneuroendocrinology. 2014;46:114-28. 